УДК 378.4

\title{
ДИСТАНЦИОННОЕ ОБУЧЕНИЕ С ИСПОЛЬЗОВАНИЕМ \\ ЭЛЕКТРОННЫХ ОРАЗОВАТЕЛЬНЫХ КУРСОВ \\ СИБИРСКОГО ФЕДЕРАЛЬНОГО УНИВЕРСИТЕТА \\ В ПЕРИОД ПАНДЕМИИ COVID-19
}

\author{
Безкоровайная Александра Игоревна \\ студент \\ Красноярский государственный \\ педагогический университет им. В.П. Астафьева \\ Пахарькова Нина Викторовна \\ к.б.н., доцент \\ Сибирский федеральный университет
}

\begin{abstract}
Аннотация: В статье рассматриваются результаты анкетирования студентов Сибирского федерального университета, обучающихся по направлению 05.03 .06 «экология и природопользования» до и после $100 \%$ дистанционного обучения в связи с пандемией COVID-19 с целью оценки их готовности получать образование с использованием дистанционных методов. Выявлено, что студенты считают наиболее эффективной смешанную форму обучения, когда преподаватель сочетает традиционные методы обучения (лекции и семинары в аудитории) и задания в электронном курсе, прежде всего, задачи и тесты.
\end{abstract}

Ключевые слова: дистанционное обучение, смешанная форма обучения, электронные образовательные курсы 


\title{
DISTANCE LEARNING USING ELECTRONIC EDUCATIONAL COURSES SIBERIAN FEDERAL UNIVERSITY DURING THE COVID-19 PANDEMIC
}

\author{
Bezkorovainaya Alexandra Igorevna \\ Krasnoyarsk State Pedagogical University named after V.P. Astafyev \\ Pakharkova Nina Viktorovna \\ Siberian Federal University
}

\begin{abstract}
The article discusses the results of a survey of students of the Siberian Federal University studying in the direction 05.03.06 "ecology and nature management" before and after $100 \%$ distance learning in connection with the COVID-19 pandemic in order to assess their readiness to receive education using distance methods. It is revealed that students consider the most effective mixed form of education when the teacher combines traditional teaching methods (lectures and seminars in the classroom) and tasks in an electronic course, primarily tasks and tests.
\end{abstract}

Key words: distance learning, mixed form of education, electronic educational courses

В современном обществе при бурном информационном росте любому специалисту требуется учиться практически всю жизнь. Сегодня идея "образования через всю жизнь" приводит к необходимости поиска новых методов передачи знаний и технологий обучения.

Дистанционное обучение - совокупность технологий, обеспечивающих доставку основного объема изучаемого материала, интерактивное взаимодействие обучаемых и преподавателей в процессе обучения, предоставление обучаемым возможности самостоятельной работы по освоению изучаемого материала, а также в процессе обучения (Андреев, 2013; Новоселова, Новоселов, 2020).

Данный вид обучение стремительно развивается во всем мире (Marks et al., 2005; Arbaugh, Benbunan-Fich, 2007; Peltier et al., 2007; Huda et al., 2018). 


\section{СОВРЕМЕННОЕ ОБРАЗОВАНИЕ: ОПЫТ ПРОШЛОГО, ВЗГЛЯД В БУДУЩЕЕ}

Преимуществом данного обучения является доступность для различных категорий обучающихся, в том числе с ограниченными возможностями, совмещение такого обучения с другими видами деятельности и индивидуальный характер обучения.

В России обучение с использованием дистанционных методов обучения является формой организации образовательного процесса, но не является формой получения образования (Вайндорф-Сысоева, Шитова, 2013). Образовательные учреждения вправе использовать дистанционные образовательные технологии при реализации образовательных программ любого уровня, а также при всех формах получения образования (их сочетании), при проведении различных видов учебных, лабораторных и практических занятий, практик (за исключением производственной практики), текущего контроля, промежуточной аттестации обучающихся.

В современных условиях, когда в стране и мире распространяется новая коронавирусная инфекция COVID-19, функционирование всех сфер жизни сильно изменилось. В целях предотвращения распространения коронавирусной инфекции Министерство просвещения и Министерство науки и высшего образования РФ рекомендовали перейти на дистанционную форму обучения (Новоселова, Новоселов, 2020). Это послужило триггером для развития и совершенствования дистанционного обучения в российских образовательных организациях разного уровня. Дальнейшее развитие систем дистанционного обучения предполагает обеспечение максимальной интерактивностью. В то же время, основными проблемами в дистанционном обучении является высокая трудоемкость разработки курсов, недостаточный опыт ведения дистанционного обучения преподавателями и слабая разработка системы контроля и идентификации обучающегося (Андреев, 2013; Магомедова, 2013; Иванов и др., 2017).

В Сибирском федеральном университете (Красноярск, Россия) в Институте экологии и географии в рамках проекта Lifelong Learning for Sustainable Development SUSDEV 574056-EPP-1-2016-1-PL-EPPKA2-CBHESP разработаны электронные образовательные ресурсы (е-курсы), в рамках которых студенты приобретают «зеленые навыки» (green skills). К ним относятся как курсы по выбору, так и курсы обязательного блока.

При реализации направления «экология и природопользование» многие дисциплины реализуются в смешанном формате, т.е. с частичным 
использованием е-курсов. Часть дисциплин реализуется традиционным методом. Переход на 100\% дистанционное обучение в марте 2020 года в связи с пандемией COVID-19 выявил неоднозначность данной формы обучения. Различия в готовности студентов и преподавателей обучаться и обучать online.

Целью исследования является оценка готовности студентов Сибирского федерального университета получать образование с использованием дистанционных методов.

Основным методом исследования является анкетирование. Разработана Анкета из 15 вопросов. Вопросы направлены на оценку со стороны студентов эффективности и качества, используемого при реализации экологических дисциплин дистанционного обучения, а также уровня знаний, получаемых при данном типе обучения. В феврале 2020 года до пандемии и ухода на дистанционное обучение было опрошено 70 респондентов 1-4 курсов, обучающихся в бакалавриате, в феврале 2021 года после выхода с дистанционного обучения было опрошено 114 респондентов 1-4 курсов.

Анкетирование показало, что практически все опрошенные студенты знают, что такое дистанционное обучение. На вопрос эффективности различных форм обучения в 2020 году до пандемии COVID-19 $66 \%$ респондентов ответили, что наиболее эффективной считают смешанную форму при совмещении традиционных и дистанционных методов, и только 4 \% отдали свой голос за дистанционную форму как наиболее эффективную. В 2021 году $14 \%$ считают наиболее эффективной дистанционную форму обучения, $59 \%$ смешанную и $27 \%$ традиционную.

Основными видами дистанционного обучения, которые использовали преподаватели в электронных курсах до пандемии, студенты назвали: решение задач или тестовых заданий - $46 \%$, лекция 34 \%. Наименьшее количество процентов набрали форум и чат - 15 и $5 \%$ соответственно (рис. 1). 


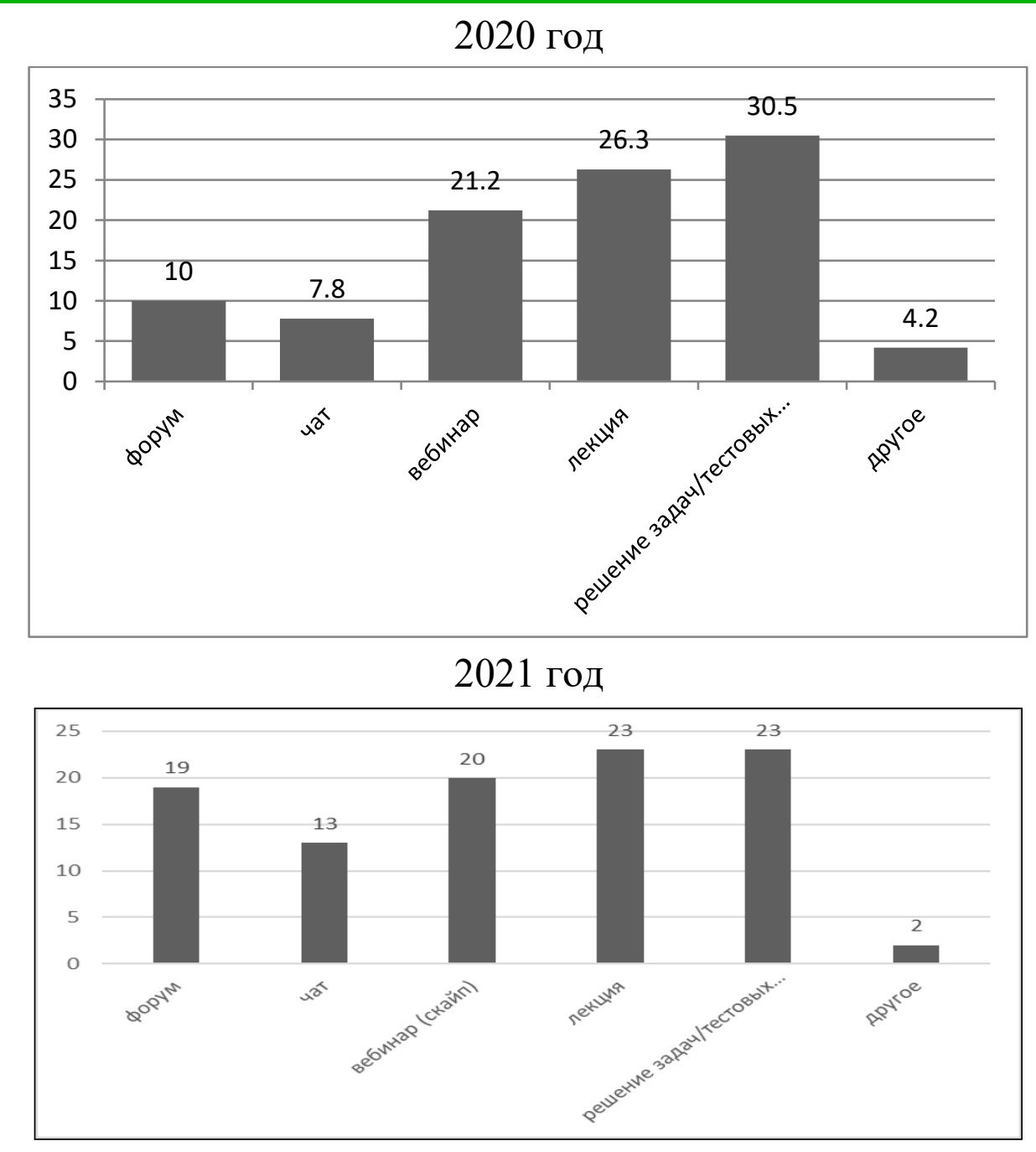

Рис. 1. Эффективность отдельных видов дистанционного обучения по мнению респондентов

После пандемии респонденты назвали лекции и решение задач/тестовых заданий самыми популярными, их выбрали 23\% и 23\% соответственно респондентов. 20\% респондентов выбрали вебинар, 19\% форум и всего $13 \%$ чат и $2 \%$ выбрали другое.

Наиболее эффективными видами обучения в е-курсах в 2020 году студенты считают решение задач и тестов (30\%), лекции (26 \%) и вебинары (21\%). Форум и чат набрали в сумме $18 \%$, что, видимо, связано со слабым использованием этого вида обучения самими преподавателями. Наиболее эффективными видами обучения в е-курсах в 2021 году студенты считают решение задач и тестовых заданий, и этот вид выбрали 29\% студентов, лекция и вебинар набрали по 26\% наименьшее количество набрали другие виды: форум $-10 \%$, чат $-7 \%$ и другое $-2 \%$. 


\section{СОВРЕМЕННОЕ ОБРАЗОВАНИЕ: ОПЫТ ПРОШЛОГО, ВЗГЛЯД В БУДУЩЕЕ}

Следующий вопрос в анкете был направлен на понимание того, улучшается ли качество реализация дисциплин с использованием е-курса в сравнении с другими дисциплинами, которые реализуются традиционно. Интересно, что до ухода на $100 \%$ дистанционное обучение среди опрошенных студентов мнение студентов разделилось почти что поровну 40 \% считают, что использование дистанционных методов улучшают качество реализуемых дисциплин, а $34 \%$ - нет. Остальные не смогли определиться (ответ «не знаю»). В 2021 студенты ответили почти что аналогично - 45\% ответили «да», 40\% - «нет», а также, 15\% не смогли определиться.

В 2020 году среди студентов $51 \%$ считали, что использование дистанционных методов не делает освоение дисциплин более сложным, по сравнению с традиционными методами. В тоже время для 36 \% включение дистанционных дисциплин усложняет обучение, $13 \%$ затруднились ответить на этот вопрос. После года 100 \% дистанционного обучения ситуация немного поменялась и $33 \%$ ответили, что освоение дисциплин в дистанционном формате делает их более сложными, $46 \%$ респондентов так не считают и ответили «нет», $11 \%$ студентов ответили «не знаю».

На вопрос «Способствует ли использование дистанционных методов обучения пониманию ключевых вопросов (понятий) изучаемой дисциплины?» почти половина респондентов ответила «да». Достаточно большая доля студентов (37 \%) считают, что электронное обучение им не помогает. Группа, респонденты которой затруднились ответить на данный вопрос, составила 14 \%. В 2021 году доля студентов, которым дистанционное обучение помогало в понимании ключевых вопросов изучаемой дисциплины, несколько выросла до $60 \%, 25 \%$ ответили «нет» и $15 \%$ не определились.

Еще один вопрос, ответ на который отражает важность и необходимость для обучающихся обратной связи в системе «преподаватель-обучающийся». Анкетирование показало, что для большей части опрошенных (61 \%) важна оценка их активности на электронных курсах. Для 26 \% опрошенных оценка не важна, и они выбрали вариант ответа «нет», остальные 13 \% затруднились, ответить на данный вопрос, и выбрали вариант «не знаю». После годичного дистанционного обучения результаты оказались приблизительно на том же уровне. Для $67 \%$ важна оценка, для $27 \%$ не важна и $6 \%$ респондентов ответили «не знаю».

Студентам было предложено выразить свое отношение к переводу всех изучаемых дисциплин в электронную среду (табл. 1). Треть студентов 


\section{СОВРЕМЕННОЕ ОБРАЗОВАНИЕ: ОПЫТ ПРОШЛОГО, ВЗГЛЯД В БУДУЩЕЕ}

ответили, что это им помогло бы планировать свое время, чуть меньшая доля студентов считают, что это усложнит их обучение и столько же выразили свое негативное отношение к заданиям в е-курсах. Как видно из таблицы, на 17 \% выросла для студентов, для которых важно самостоятельно планировать свое время и значительно снизилась доля студентов, которым не нравится выполнять задания дистанционно на е-курсе.

На рисунке 2 отражены результаты ответов на вопрос о готовности студентов-экологов перейти на дистанционное обучение.

Таблица 1

Отношение студентов к переводу всех изучаемых дисциплин

в электронную среду

\begin{tabular}{|c|c|c|c|}
\hline Вопрос & Предложенные ответы & $\% 2020$ г & $\% 2021 \Gamma$ \\
\hline \multirow{5}{*}{$\begin{array}{l}\text { Как вы отнесетесь к } \\
\text { тому, что все } \\
\text { дисциплины будут } \\
\text { переведены в } \\
\text { электронную форму }\end{array}$} & $\begin{array}{l}\text { Это будет здорово, я } \\
\text { смогу самостоятельно } \\
\text { планировать свое } \\
\text { время }\end{array}$ & 30,8 & $48 \%$ \\
\hline & $\begin{array}{l}\text { Это усложнит мое } \\
\text { обучение }\end{array}$ & 27,2 & $26 \%$ \\
\hline & $\begin{array}{l}\text { Мне вообще не } \\
\text { нравится выполнять } \\
\text { задания в е-курсах }\end{array}$ & 27,2 & $10 \%$ \\
\hline & Мне все равно & 7,4 & $6 \%$ \\
\hline & Другое & 7,4 & $10 \%$ \\
\hline
\end{tabular}

Больше половины респондентов (63\%) согласны изучать дистанционно только отдельные дисциплины, например, курсы по выбору, т.е. не базовые дисциплины (рис. 2). Как показали, предыдущие ответы, наиболее приемлемым для себя студенты считают использование как традиционных методов обучения (лекции и семинары в аудитории). Только 16 \% готовы полностью обучаться дистанционно при гарантированном получении диплома о соответствующем образовании. При этом, следует отметить, что 21 \% опрошенных студентов выразили свое негативное отношение к дистанционному обучению и отметили в анкете ответ «нет». В 2021 году наибольшее количество голосов набрал ответ «нет», а это значит, что студенты не готовы обучаться дистанционно. 35\% хотели бы изучать отдельные дисциплины (например курсы по выбору). 20\% студентов хотели 
бы обучаться дистанционно полностью с получением диплома, а это выше, чем в 2019 году (рис. 2).
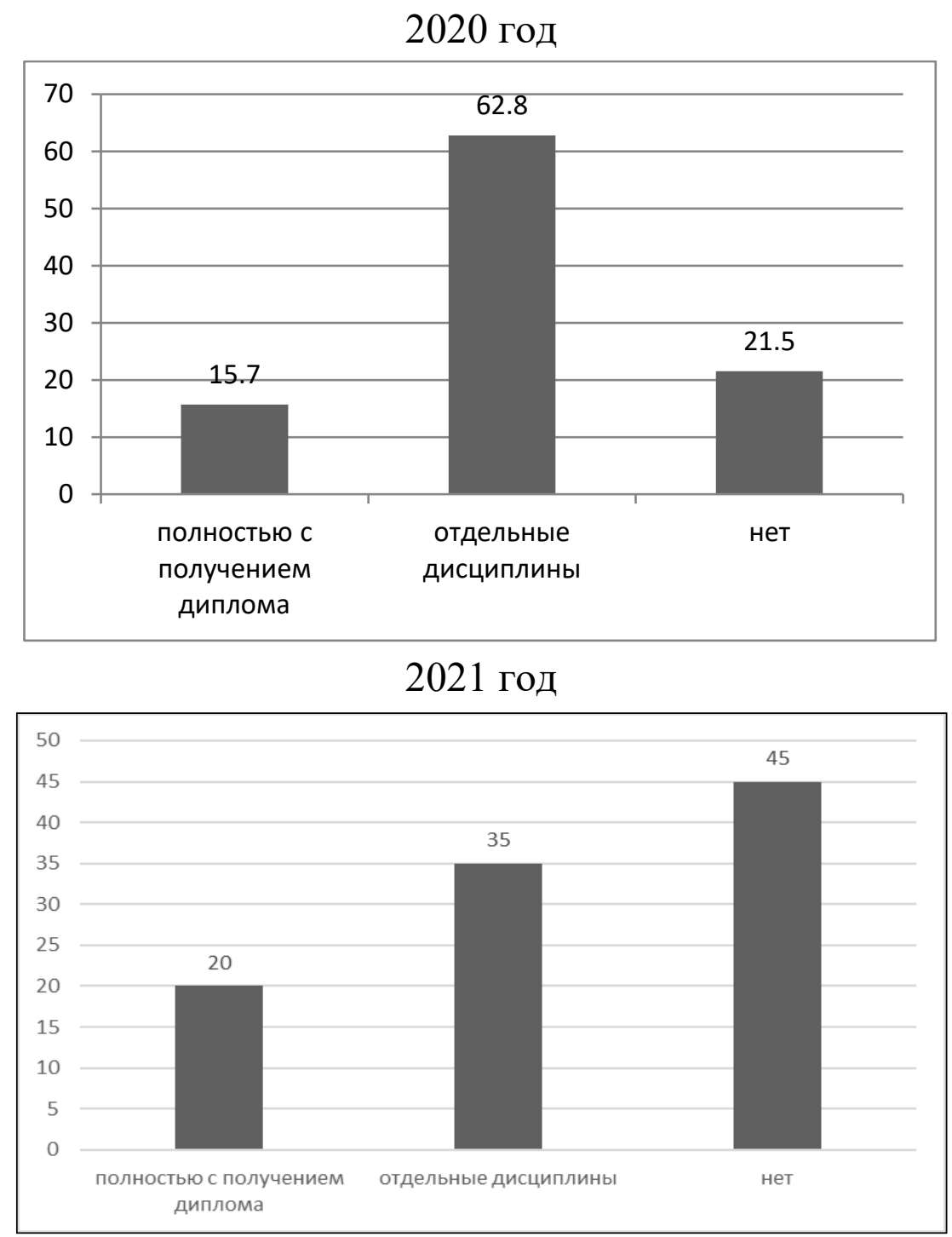

\section{Рис. 2. Соотношение ответов на вопрос «Готовы ли вы обучаться дистанционно?»}

Анализ проведенного анкетирования в целом показал, что студенты, обучающиеся по направлению «экология и природопользование» считают наиболее эффективной смешанную форму обучения, когда преподаватель сочетает традиционные методы обучения (лекции и семинары в аудитории) и задания в электронном курсе, прежде всего задачи и тесты. При этом для большинства студентов важно наличие обратной связи, а также оценка и комментарии преподавателя при выполнении заданий. Выявлены 


\section{СОВРЕМЕННОЕ ОБРАЗОВАНИЕ: ОПЫТ ПРОШЛОГО, ВЗГЛЯД В БУДУЩЕЕ}

противоречия в ответах студентов. С одной стороны, перевод всех дисциплин в дистанционный формат, они отмечают, как положительный факт - иметь больше свободного времени и планировать свою работу самостоятельно. С другой стороны, дистанционное обучение в период пандемии, вызванной COVID-19, выявило негативное отношение обучающихся к 100\% переходу на данную форму.

\section{Примечание}

Работа выполнена при финансовой поддержке Исполнительного агентства по образованию, культуре и аудиовизуальным средствам Европейской Комиссии, грант Lifelong Learning for Sustainable Development SUSDEV 574056-EPP-1-2016-1-PL-EPPKA2-CBHE-SP

\section{Список литературы}

1. Андреев А. А. Дистанционное обучение и дистанционные образовательные технологии //Открытое образование. - 2013. - №. 5. С. 40-46.

2. Вайндорф-Сысоева М. Е., Шитова В. А. О моделях применения дистанционных образовательных технологий в современном вузе //Педагогика и психология образования. - 2013. - №. 4.

3. Иванов С. В., Иванов, И. С., Цуканов, А. В., Жабин, С. Н. Дистанционные методы контроля оценки обучения //Образовательный процесс: поиск эффективных форм и механизмов. - 2017. - С. 253.

4. Корнеев Д. Н., Корнеева Н. Ю. реализации дистанционных образовательных технологий в профессиональном образовании // Главный редактор: НА Краснова Технический редактор: ЮО Канаева. - 2018.

5. Магомедова Р. М. Организационные условия формирования профессиональных компетенций преподавателя вуза в процессе послевузовской подготовки //Вестник Томского государственного педагогического университета. - 2013. - №. 1 (129).

6. Новоселова Д. В., Новоселов Д. В. Дистанционное обучение в условиях пандемии // Теория и практика социогуманитарных наук. - 2020. №. 3 (11). - С. 35-39.

7. Arbaugh J. B., Benbunan-Fich R. The importance of participant interaction in online environments // Decision support systems. - 2007. - T. 43. №. 3. - C. 853-865. 
8. Marks R. B., Sibley S. D., Arbaugh J. B. A structural equation model of predictors for effective online learning // Journal of management education. - 2005. - T. 29. - №. 4. - C. 531-563.

9. Peltier J. W., Schibrowsky J. A., Drago W. The interdependence of the factors influencing the perceived quality of the online learning experience: A causal model // Journal of Marketing Education. - 2007. - T. 29. - №. 2. - C. 140-153.

10. Huda, M., Maseleno, A., Atmotiyoso, P., Siregar, M., Ahmad, R., Jasmi, K., \& Muhamad, N. (2018). Big data emerging technology: insights into innovative environment for online learning resources. International Journal of Emerging Technologies in Learning (iJET), 13(1), 23-36.

() А.И. Безкоровайная, Н.В. Пахарькова, 2021 